\title{
Fast northward energy transfer in the Atlantic due to Agulhas rings
}

\section{Article}

Published Version

van Sebille, E. and van Leeuwen, P. J. (2007) Fast northward energy transfer in the Atlantic due to Agulhas rings. Journal of Physical Oceanography, 37 (9). pp. 2305-2315. ISSN 00223670 doi: https://doi.org/10.1175/JPO3108.1 Available at https://centaur.reading.ac.uk/24131/

It is advisable to refer to the publisher's version if you intend to cite from the work. See Guidance on citing.

To link to this article DOI: http://dx.doi.org/10.1175/JPO3108.1

Publisher: American Meteorological Society

All outputs in CentAUR are protected by Intellectual Property Rights law, including copyright law. Copyright and IPR is retained by the creators or other copyright holders. Terms and conditions for use of this material are defined in the End User Agreement.

\section{www.reading.ac.uk/centaur}

\section{CentAUR}

Central Archive at the University of Reading

Reading's research outputs online 


\title{
Fast Northward Energy Transfer in the Atlantic due to Agulhas Rings
}

\author{
ERIK VAN SEBILlE AND PETER JAN VAN LEEUWEN \\ Institute for Marine and Atmospheric Research Utrecht, Utrecht University, Utrecht, Netherlands
}

(Manuscript received 21 April 2006, in final form 2 October 2006)

\begin{abstract}
The adiabatic transit time of wave energy radiated by an Agulhas ring released in the South Atlantic Ocean to the North Atlantic Ocean is investigated in a two-layer ocean model. Of particular interest is the arrival time of baroclinic energy in the northern part of the Atlantic, because it is related to variations in the meridional overturning circulation. The influence of the Mid-Atlantic Ridge is also studied, because it allows for the conversion from barotropic to baroclinic wave energy and the generation of topographic waves. Barotropic energy from the ring is present in the northern part of the model basin within 10 days. From that time, the barotropic energy keeps rising to attain a maximum 500 days after initiation. This is independent of the presence or absence of a ridge in the model basin. Without a ridge in the model, the travel time of the baroclinic signal is 1300 days. This time is similar to the transit time of the ring from the eastern to the western coast of the model basin. In the presence of the ridge, the baroclinic signal arrives in the northern part of the model basin after approximately 10 days, which is the same time scale as that of the barotropic signal. It is apparent that the ridge can facilitate the energy conversion from barotropic to baroclinic waves and the slow baroclinic adjustment can be bypassed. The meridional overturning circulation, parameterized in two ways as either a purely barotropic or a purely baroclinic phenomenon, also responds after 1300 days. The ring temporarily increases the overturning strength. The presence of the ridge does not alter the time scales.
\end{abstract}

\section{Introduction}

The spatial and temporal distribution of temperature and salt within the Atlantic Ocean is determined by many processes. In this article, the focus is on two of these. One is the North Atlantic Deep Water (NADW) formation near Greenland (e.g., Schmitz 1995; Ganachaud and Wunsch 2000) and the associated concept of the meridional overturning circulation (MOC). The other is the mixing of warm and salty Indian Ocean water into the Atlantic near South Africa in the form of Agulhas leakage (e.g., Gordon 1986; Lutjeharms 1996; De Ruijter et al. 1999; Boebel et al. 2003; De Ruijter et al. 2005).

The MOC is the global-scale circulation with enhanced downwelling in the Labrador Sea and near Greenland, and upwelling in the Antarctic Circumpolar Current (ACC), the Indian Ocean, and the Pacific

Corresponding author address: Erik van Sebille, Institute for Marine and Atmospheric Research Utrecht, Princetonplein 5, 3584 CC Utrecht, Netherlands.

E-mail: sebille@phys.uu.nl
Ocean. Although the exact mechanisms behind the MOC are still disputed (see, e.g., Rahmstorf 1996), the forcing is thought to be the meridional density difference in the Atlantic Ocean (see, e.g., Weijer et al. 2002) Ganachaud and Wunsch (2000) estimate the strength of the NADW formation as $15 \pm 2 \mathrm{~Sv}\left(1 \mathrm{~Sv} \equiv 10^{6} \mathrm{~m}^{3} \mathrm{~s}^{-1}\right)$ and the northward heat flux that is associated with this circulation as about $1.3 \mathrm{PW}\left(1 \mathrm{PW} \equiv 10^{15} \mathrm{~W}\right)$. This warms Europe by approximately $10 \mathrm{~K}$ (Rahmstorf and Ganopolsky 1999), making the climate in Europe sensitive to changes in the strength of the MOC (Broecker 1997; Clark et al. 2002).

In the surface return flow of the MOC, Agulhas rings are the link between the Indian and the Atlantic Ocean (Gordon 1986). The warm and saline western boundary Agulhas Current flows poleward to Cape Agulhas, where it retroflects back into the Indian Ocean. In this retroflection area, large Agulhas rings are being shed that move into the South Atlantic. These eddies are thought to play a crucial role in the total MOC (see, e.g., De Ruijter et al. 1999, and references therein). In their variability, they form a key link in climate change processes such as (de)glaciations as the relatively high

DOI: $10.1175 / J P O 3108.1$ 
salinity of the Indian Ocean can precondition the Atlantic Ocean waters involved in the NADW (Knorr and Lohmann 2003; Peeters et al. 2004).

It has been attempted before to quantify the influence of Agulhas rings on the MOC strength. Weijer et al. (2002) used a low-resolution (3.5 in zonal and meridional direction) and highly diffusive global circulation model to study the response of the overturning strength on a heat and salt anomaly located in the southern Atlantic Ocean. The legitimacy of using such a model can be disputed, as waves and currents are not well represented, thereby strongly underestimating the advective transport of energy. This energy transfer through waves can, however, be an important factor in baroclinic processes such as the MOC (e.g., Saenko et al. 2002).

The way in which perturbations can radiate energy through a basin was investigated by Johnson and Marshall $(2002 \mathrm{a}, \mathrm{b})$. In their high-resolution reduced gravity model the authors show that perturbations (modeled to represent sudden changes in the overturning) can, via a consecutive chain of Kelvin and Rossby waves, transport energy over an entire basin and even between hemispheres. Primeau (2002) and Cessi and Otheguy (2003) also discuss the way in which energy input by Southern Ocean winds is redistributed in a doublehemisphere ocean basin.

The questions addressed herein focus first of all on the time scale on which an Agulhas ring can adiabatically (i.e., only through its dynamical structure) influence the wave activity and kinetic energy in the North Atlantic. Because of the baroclinic nature of the MOC, the time scale of main interest will be that of the baroclinic mode. We will therefore focus on the amount of baroclinic energy available in the northernmost part of the North Atlantic Ocean.

Second, the influence of the Mid-Atlantic Ridge on this time scale will be discussed. The influence of such ridges on both barotropic and baroclinic waves has been discussed before (e.g., Wang and Koblinsky 1994; Barnier 1988; Tailleux and McWilliams 2000; Tailleux 2004). Moreover, many authors (Kamenkovitch et al.
1996; Beismann et al. 1999) have already shown that a ridge can significantly deform an Agulhas ring. When the ring is deformed, baroclinic energy is released from the ridge increasing the amount of available baroclinic energy. The ridge can also facilitate the conversion from barotropic to baroclinic wave energy. When this happens in the North Atlantic, it can result in a significant decrease of the travel time since it bypasses the relatively slow baroclinic waves traveling through the South Atlantic basin.

To this end, a two-layer primitive equations model was used. By releasing a ring in the southern part of the domain, the dynamical response of the system is modeled. The time it takes for this ring energy to arrive in the northernmost part of the model Atlantic basin is used as a proxi for the response time of the MOC.

The MOC can also be implemented in the model and in this way the direct effect of the rings on the overturning strength can be studied. It is difficult to parameterize a diabatic phenomenon such as the overturning circulation in an adiabatic two-layer model and therefore two different approaches have been taken. Although they both have their imperfections, the results are to some extent similar and confirm each other.

The structure of this article is as follows: in section 2, the two-layer model is discussed, together with the implementation of the Agulhas ring. Section 3 presents the results concerning the time scales of the responses and the role of the Mid-Atlantic Ridge. Section 4 discusses the impact of the ring on the two different parameterizations of the MOC. The summary and discussion are given in section 5. The appendix introduces the two different parameterizations for the MOC in a twolayer model.

\section{The model}

To facilitate both a baroclinic and a barotropic mode, a two-layer model has been implemented. The governing equations in this model are the primitive equations for a layer $i=\{1,2\}$ :

$$
\begin{aligned}
\frac{\partial u_{i}}{\partial t}-v_{i}\left(\zeta_{i}+f\right)+\frac{1}{2} \frac{\partial\left(u_{i}^{2}+v_{i}^{2}\right)}{\partial x} & =-P(x)+D\left(\frac{\partial^{2} u_{i}}{\partial x^{2}}+\frac{\partial^{2} u_{i}}{\partial y^{2}}\right), \\
\frac{\partial v_{i}}{\partial t}+u_{i}\left(\zeta_{i}+f\right)+\frac{1}{2} \frac{\partial\left(u_{i}^{2}+v_{i}^{2}\right)}{\partial y} & =-P(y)+D\left(\frac{\partial^{2} v_{i}}{\partial x^{2}}+\frac{\partial^{2} v_{i}}{\partial y^{2}}\right), \quad \text { and } \\
\frac{\partial h_{i}}{\partial t} & =\frac{\partial u_{i} h_{i}}{\partial x}+\frac{\partial v_{i} h_{i}}{\partial y},
\end{aligned}
$$


in which $\zeta_{i}=\left(\partial v_{i} / \partial x\right)-\left(\partial u_{i} / \partial y\right)$ is the relative vorticity and $D$ is the viscosity coefficient. The pressure term $P(k)$ is formulated as

$$
P(k)=\left\{\begin{array}{cc}
g \frac{\partial \eta_{1}}{\partial k} & \text { for } \quad i=1 \\
g \frac{\partial \eta_{1}}{\partial k}+\Delta \rho g \frac{\partial \eta_{2}}{\partial k} & \text { for } \quad i=2
\end{array} .\right.
$$

The interface elevation $\eta_{i}$ is related to the layer thickness $h_{i}$ through

$$
h_{i}=\eta_{i}-\eta_{i+1}+H_{i},
$$

with the condition that $\eta_{3}=0$. Here $H_{i}$ is the undisturbed layer thickness, $H_{1}=500 \mathrm{~m}$, and $H_{2}=4000 \mathrm{~m}$. The reduced density is $\Delta \rho=\left(\rho_{2}-\rho_{1}\right) / \rho_{1}=0.002$.

The equations are integrated on a domain of $60^{\circ}$ in the zonal and $120^{\circ}$ in the meridional direction, where the equator is centered halfway up the model basin. The governing equations are discretized on an Arakawa C-grid (Mesinger and Arakawa 1976; Kowalik and Murty 1993) with $25-\mathrm{km}$ spacing in both the meridional and zonal direction. This resolution is still eddy permitting at $30^{\circ}$ where the Rossby radius of deformation is $40 \mathrm{~km}$. The time step is $40 \mathrm{~s}$.

Curvature terms have been neglected. As pointed out by Cessi and Otheguy (2003), this is allowed as long as the frequency of the Rossby waves is low. In that case, the metric terms $\cos (\phi)$ in the phase speed and the term that relates distance to longitude cancel each other. The time it takes for a signal to zonally cross the ocean basin is therefore equal in this model to that in a full spherical model.

Some experiments require the presence of a MidAtlantic Ridge. This ridge is implemented as a 1000-mhigh obstacle meridionally oriented halfway across the model basin. The ridge height falls linearly to zero over $500 \mathrm{~km}$. The entire model basin geometry and bathymetry are depicted in Fig. 1.

At the eastern and western boundary a no-slip boundary condition $(u=v=0)$ is prescribed. Changing the boundary condition to free slip (where $\partial v / \partial y=u=$ 0 ) does not change the main features of the response. The boundary conditions on the northern and southern boundary are also free slip. Note that this implies that the southern boundary could act as a waveguide for Kelvin waves. This is unwanted, as the southern boundary represents the connection with the circumpolar Southern Ocean. Tests, however, have shown that the zonal flux of energy through the southernmost $100 \mathrm{~km}$ of the domain is only $3 \%$ of the total zonal flux.

The Agulhas ring is modeled as a Gaussian-shaped mass perturbation with an $e$-folding length scale of

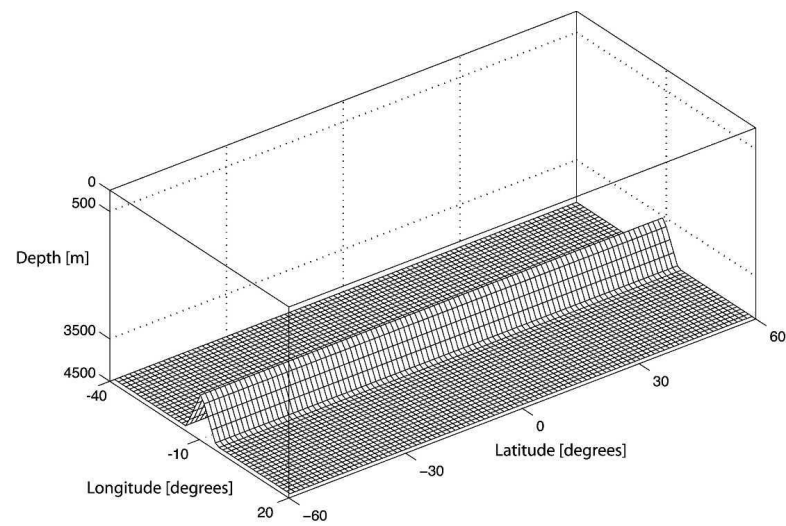

FIG. 1. The geometry and bathymetry of the model. The northern and southern boundaries are at $60^{\circ} \mathrm{N}$ and $60^{\circ} \mathrm{S}$ and the eastern and western boundaries are at $40^{\circ} \mathrm{W}$ and $20^{\circ} \mathrm{E}$, respectively. The meridional ridge is incorporated in one of the two model configurations.

$112 \mathrm{~km}$. The maximum sea surface elevation is $\eta_{1}^{\max }=50 \mathrm{~cm}$ and the corresponding interface declination is $\eta_{2}^{\max }=-200 \mathrm{~m}$. The ring is not in isostatic equilibrium (since $\eta_{1}^{\max }>-\eta_{2}^{\max } \Delta \rho$ ), but is corotating. All values are taken to represent a typical Agulhas ring (Van Aken et al. 2003; Drijfhout et al. 2003).

To minimize gravity wave noise upon initialization, the ring has a prescribed cyclogeostrophic velocity field. In such a velocity field, the Coriolis force is balanced by both the pressure gradient force and the centrifugal force (De Steur et al. 2004). At initiation, therefore, the ring is corotating with maximum velocities $V_{1}=0.6 \mathrm{~m} \mathrm{~s}^{-1}$ and $V_{2}=0.1 \mathrm{~m} \mathrm{~s}^{-1}$ in the upper and lower layer, respectively. The ring is released without any initial translational velocity at $30^{\circ} \mathrm{S}, 10^{\circ} \mathrm{E}$.

\section{Energy transfer time scales}

\section{a. The flat-bottom case}

The model described in the previous section has been integrated over 2500 days for the model configuration without a meridional ridge. Figures 2 and 3 depict the sea surface height and interface elevation after 100 , 800,1500 , and 2200 days of running the model. To appreciate the fine structure of the deviations, the figures have been cut off to only $0.5 \%$ of the initial maximum sea surface height and interface depression (i.e., $2.5 \times 10^{-3} \mathrm{~m}$ and $1.0 \mathrm{~m}$, respectively).

In the figures, the ring can clearly be seen moving westward because of the $\beta$ effect (see, e.g., Nof 1983). From consecutive snapshots, the phase velocity of the Agulhas ring can be estimated at $3.8 \mathrm{~cm} \mathrm{~s}^{-1}$. This is in good agreement with the theoretical value for an anti- 

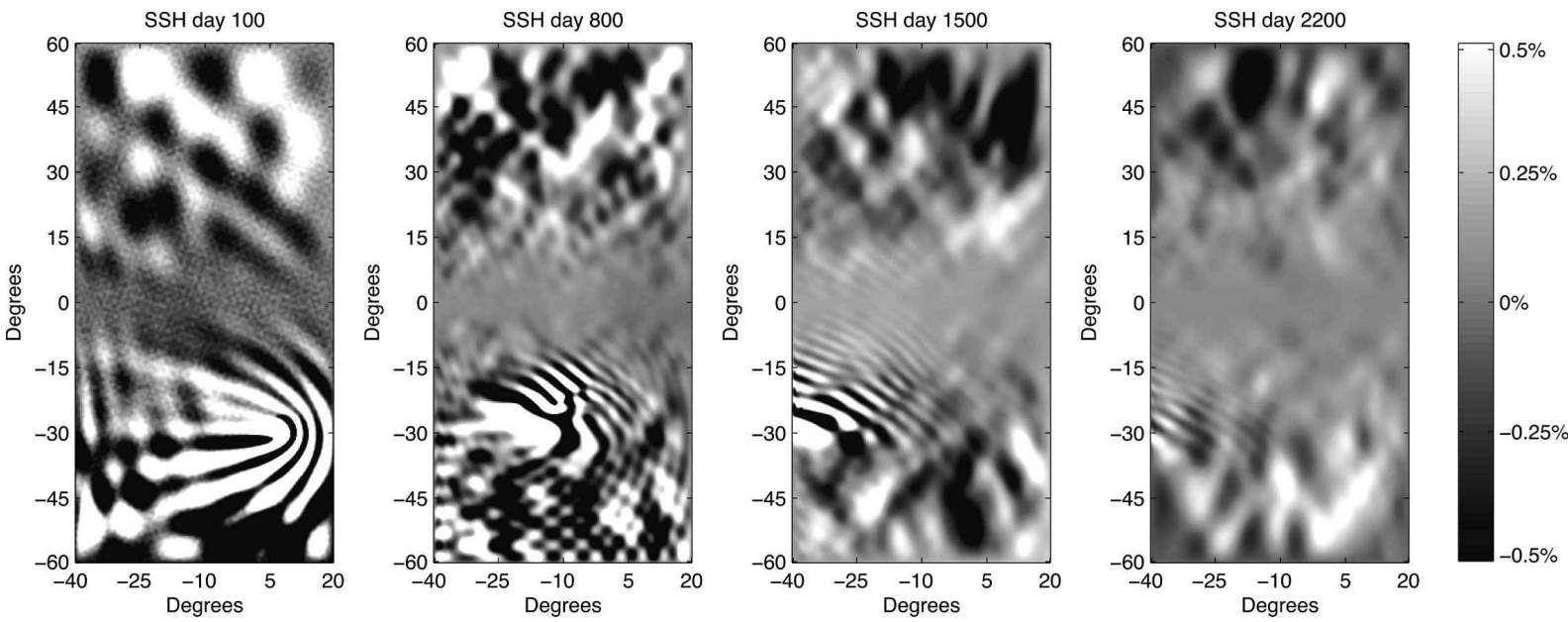

FIG. 2. Four snapshots of the sea surface height in the model run without a ridge. The scale runs from $-0.5 \%$ to $0.5 \%$ of the initial maximum ring height $(0.5 \mathrm{~m})$. The ring slowly moves westward, radiating short $\left(\lambda \ll R_{d}\right)$ Rossby waves in an envelope.

cyclone, a bit larger than the baroclinic Rossby wave speed of $c=\beta R_{d}^{2}=3.67 \mathrm{~cm} \mathrm{~s}^{-1}$ at $30^{\circ} \mathrm{S}$, with $R_{d}$ as the (first) internal Rossby radius of deformation. The decay of the maximum sea surface height of the perturbation is shown in Fig. 4. In the first 300 days, the decay is similar to the decay of Agulhas rings as observed from satellite altimetry (Schouten et al. 2000). After this time, the ring in the model keeps disintegrating, to equilibrate at a lower height than the rings found by Schouten et al. (2000). From these considerations, it can be concluded that the implementation and resulting behavior of the perturbation in this study is in sufficient resemblance with what is known about Agulhas ring dynamics from observations and theory.
When the ring reaches the western boundary of the model basin, the ring energy is transformed to a Kelvin adjustment wave. Liu et al. (1999) discuss the transformation from Rossby waves to Kelvin waves and show that the Kelvin adjustment wave is capable of transporting mass northward to the equator. This can be seen in Fig. 3, where the interface behind the Rossby basin mode wave is depressed. This is a redistribution of the negative mass anomaly of the Agulhas ring.

At the equator, the coastal Kelvin adjustment wave will travel eastward as an equatorial Kelvin adjustment wave. After the mass anomaly has reached the eastern side of the domain, two Kelvin adjustment waves will deflect poleward. As they deflect, the resulting eastern
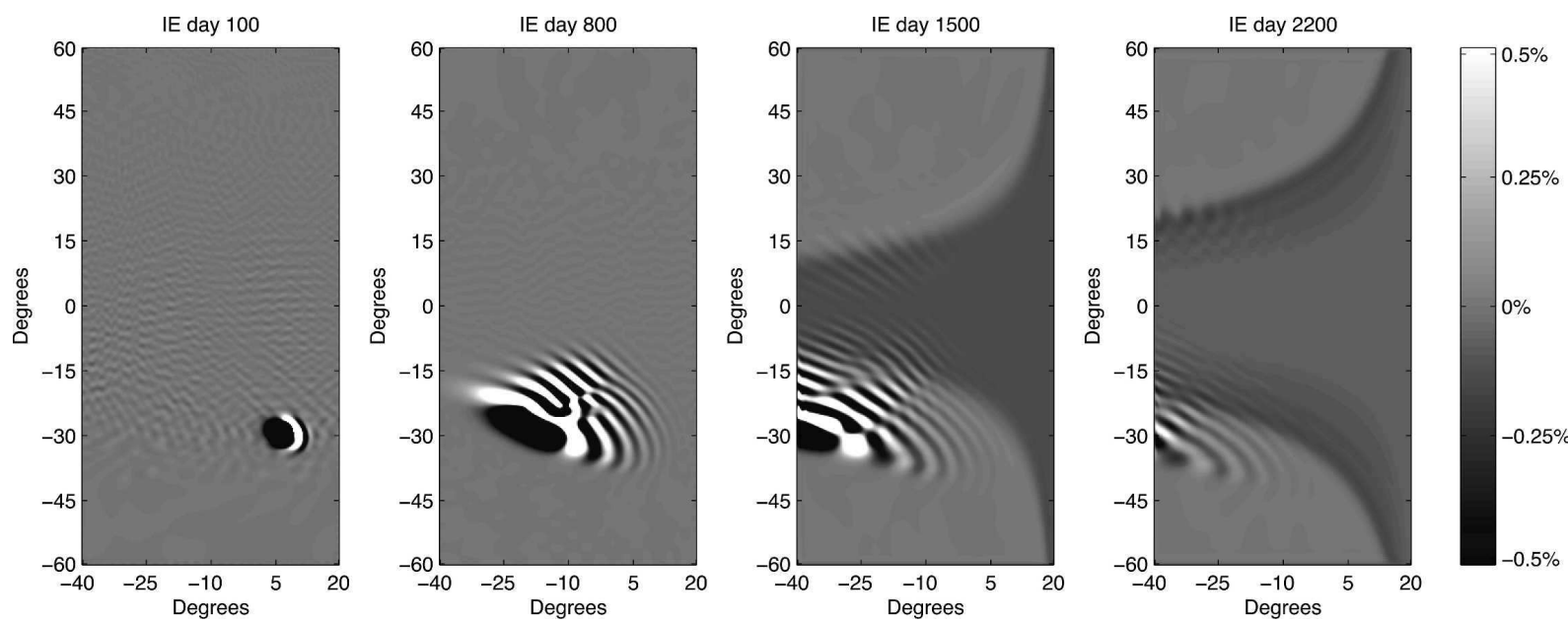

FIG. 3. Four snapshots of the interface elevation in the model run without a ridge. The scale runs from $-0.5 \%$ to $0.5 \%$ of the initial maximum interface depression $(200 \mathrm{~m})$. The ring slowly moves westward and as it hits the western boundary, Kelvin waves transport mass along the equator to the eastern coast where a Rossby basin mode emerges. 


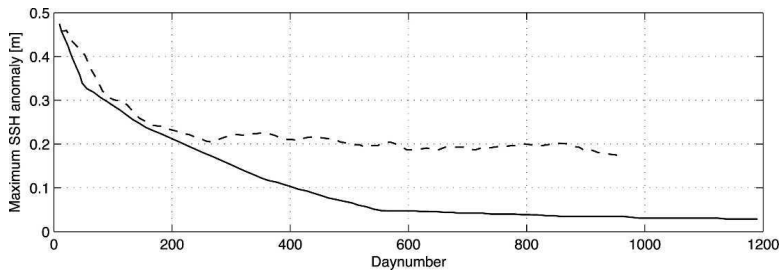

FIG. 4. The decay of the maximum sea surface height of the ring as a function of time in this model (solid) and as found by Schouten et al. (2000) from satellite altimetry (dashed).

coastal Kelvin adjustment waves will radiate long Rossby waves into the basin. The sequence of incoming equatorial Kelvin waves to poleward Kelvin waves and long westward Rossby waves has previously been described by Anderson and Rowlands (1976) and it has also been reported by Johnson and Marshall (2002b) and Primeau (2002) in their model studies.

The snapshots of the sea surface height (Fig. 2) reveal that the response time for the barotropic mode of the Agulhas ring is short, as energy (sea surface variation) is already present in the North Atlantic region after 100 days. To better quantize the amount of energy present, Fig. 5 shows the mean barotropic energy between $45^{\circ}$ and $55^{\circ} \mathrm{N}$ as a function of time. Within 10 days, the amount of barotropic energy starts to rise sharply. The response of the ocean to a small perturbation $\left(\lambda \ll \bar{R}_{d}\right.$, with $\bar{R}_{d}$ as the external Rossby radius of deformation) has previously been addressed by Longuet-Higgins (1965) and Tang (1979). They showed that the energy will be radiated in an envelope to all directions with the maximal Rossby wave phase speed, $c=\beta \bar{R}_{d}^{2}$, which leads to a travel time of less than a day from $30^{\circ} \mathrm{S}$ to $50^{\circ} \mathrm{N}$.

The amount of barotropic energy attains a maximum value after 500 days. To explain this time scale, two effects have to be taken into account. In the first 500 days, the ring height decreases drastically (see Fig. 4). During this decay, energy is released into the basin, yielding an increase of the amount of barotropic energy away from the ring. After 500 days, the ring decay slows down, and only a little extra energy is radiated. On the other hand, the continuous dissipation of energy decreases the total amount of energy in the basin. These two effects oppose each other and explain the peak in barotropic energy after 500 days.

From the snapshots of the interface elevation, Fig. 3, it appears that the mass anomaly associated initially with the Agulhas ring has reached the northernmost part of the model basin after 1500 days. This is confirmed in Fig. 6, where the baroclinic energy between $45^{\circ}$ and $55^{\circ} \mathrm{N}$ is depicted as a function of time. Note that the scales of Figs. 5 and 6 are a factor of $10^{3}$ different.

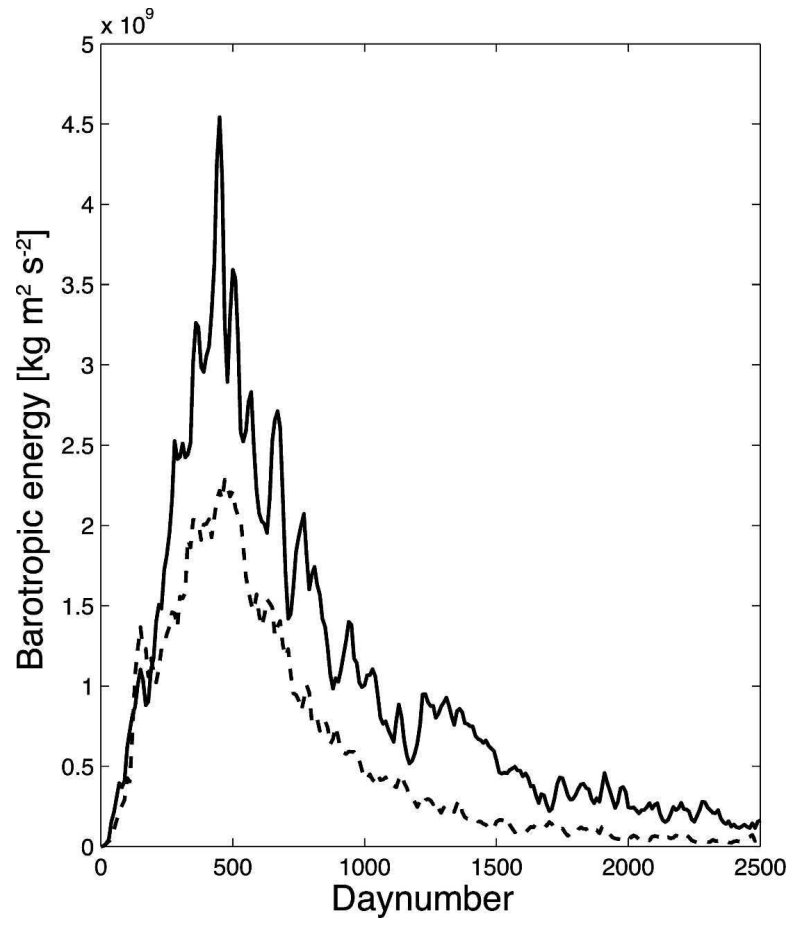

FIG. 5. The mean barotropic kinetic energy between $45^{\circ}$ and $55^{\circ} \mathrm{N}$ as a function of time for the model run without (solid) and with (dashed) a ridge.

This is due to the fact that the barotropic energy reaches the northernmost part of the basin much sooner than the baroclinic energy. When the baroclinic signal arrives, much of the energy has dissipated.

The high peak within the first 100 days in Fig. 6 is due to the fact that the ring is still not in perfect equilibrium and radiates inertial gravity waves that quickly dissipate. These inertial gravity waves are also present in the barotropic energy, but cannot be distinguished because of the much larger energy scale of the Rossby waves.

The figure shows that when the gravity wave noise has dissipated, the baroclinic energy level is negligible until day number 1300 . From then on, the baroclinic energy rises as the eastern coastal Kelvin adjustment wave arrives at $45^{\circ} \mathrm{N}$. The level of baroclinic energy remains significant until the end of the experiment. Ignoring the early-stage inertial gravity wave noise, the response time of the baroclinic mode can be estimated to 1300 days. Note that because of the high phase speed of the coastal Kelvin wave relative to the Rossby wave phase speed, the second dominates this time scale. In other words, it is the time it takes the ring to zonally cross the model basin that largely determines the time scale. 


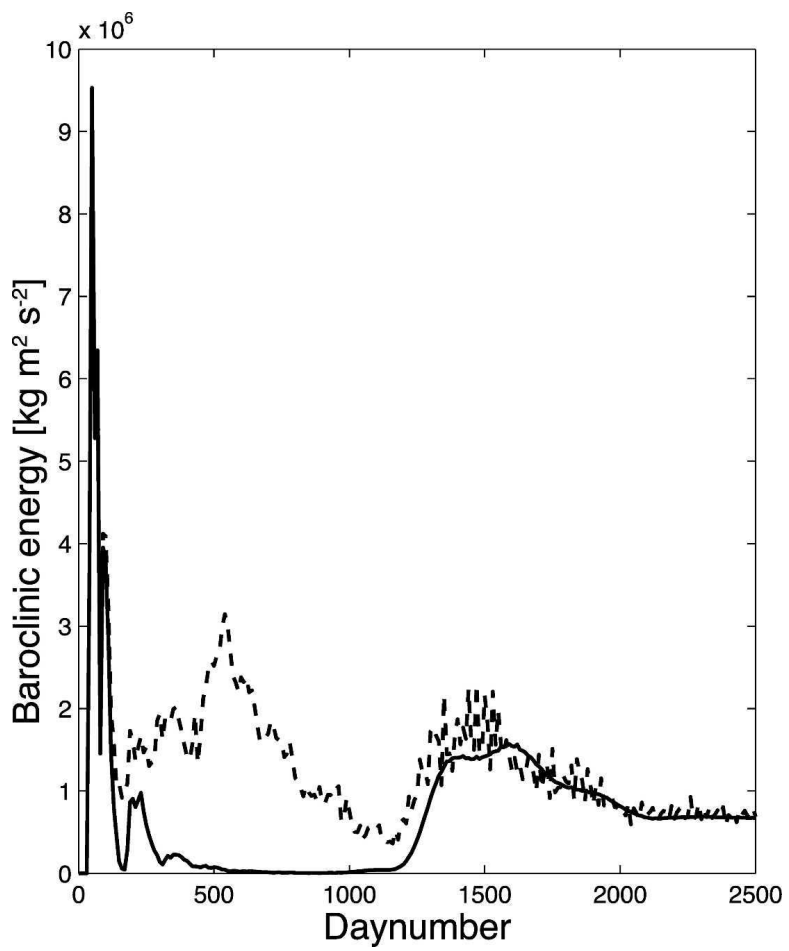

FIG. 6. The mean baroclinic kinetic energy between $45^{\circ}$ and $55^{\circ} \mathrm{N}$ as a function of time for the model run without (solid) and with (dashed) a ridge. After 1300 days, the baroclinic energy in the flat-bottom case rises as the coastal Kelvin adjustment wave arrives in the northern part of the basin. The response time of the baroclinic mode without a ridge is therefore 1300 days. If a ridge is included, the level of energy is high from initiation onward and the response time is comparable to that of the barotropic energy. Note the difference in vertical scale with Fig. 5.

\section{b. The meridional ridge case}

The next question is how the travel times are altered by the meridional ridge. Figure 7 depicts four snapshots of the sea surface height in the configuration with a ridge. It is clearly visible that the barotropic energy is to some extent obstructed by the ridge. After 100 days, there is a difference in sea surface height variance between the eastern and the western half of the model basin. As the ring itself crosses the ridge, after approximately 800 days, the energy can be released in the western half of the basin.

Figure 8 shows snapshots for the interface elevation from the model run with a ridge. In the first snapshot, it can be seen that the ridge forces baroclinic topographic waves. There is significant energy on the ridge just west of the ring, where the barotropic energy is also at its maximum (see Fig. 7). As the ring passes the ridge, it completely deforms. However, this has little consequence for the evolution of the interface basin mode Rossby wave as depicted in the last two snap- shots. The snapshots are very similar to those of the flat-bottom model run.

The dashed line in Fig. 5 shows the barotropic energy in the northernmost part of the model basin from the run including the ridge. The level of barotropic energy is generally lower than in the run without the ridge. The baroclinic energy in Fig. 6, on the other hand, is higher than in the flat-bottom run. This supports the idea that the ridge can indeed facilitate the conversion from barotropic to baroclinic energy. After 1800 days, when the baroclinic Rossby basin mode is well established, this effect is suppressed and there is almost no difference between model runs with and without a ridge. The barotropic energy level remains lower than in the flatbottom case, indicating stronger dissipation on the ridge.

The amount of baroclinic energy does not drop to zero after the gravity wave noise has dissipated, after 400 days. Instead, it is at a level comparable to that of the response after 1300 days in the flat-bottom run. One can therefore conclude that the time scale is drastically shortened by the ridge. It is unfortunate that the initial noise obscures the situation for the first 100 days, but it is reasonable to estimate that the response time of the baroclinic mode is in this case equal to that of the barotropic mode (i.e., on the order of 10 days).

Figure 8 gives the impression that baroclinic topographic Rossby waves are responsible for the northward transport of baroclinic wave energy. However, the group velocity of these waves is much too small to support the fast response in the Northern Hemisphere. Instead, the baroclinic wave energy in the Northern Hemisphere is locally generated by energy conversion of barotropic to baroclinic waves at the ridge. This view is supported by the peak of the baroclinic energy around day 500 (cf. Fig. 6 with Fig. 5).

\section{Response of the MOC}

In the previous section the responsive time-scale circulations of the transfer of energy from the southern to the northern Atlantic Ocean have been discussed. However, it is still debatable whether the energy that is associated with the ring is sufficient to affect the strength of the MOC significantly.

In an attempt to test the quantitative response of the MOC on an Agulhas ring, two different implementations of this circulation have been developed: a pressure-driven and a flux-driven parameterization. The first parameterization uses the zonally averaged barotropic pressure difference between the Southern and Northern Hemisphere and the second uses the baroclinic meridional mass flux at $40^{\circ} \mathrm{N}$. Both parameteriza- 

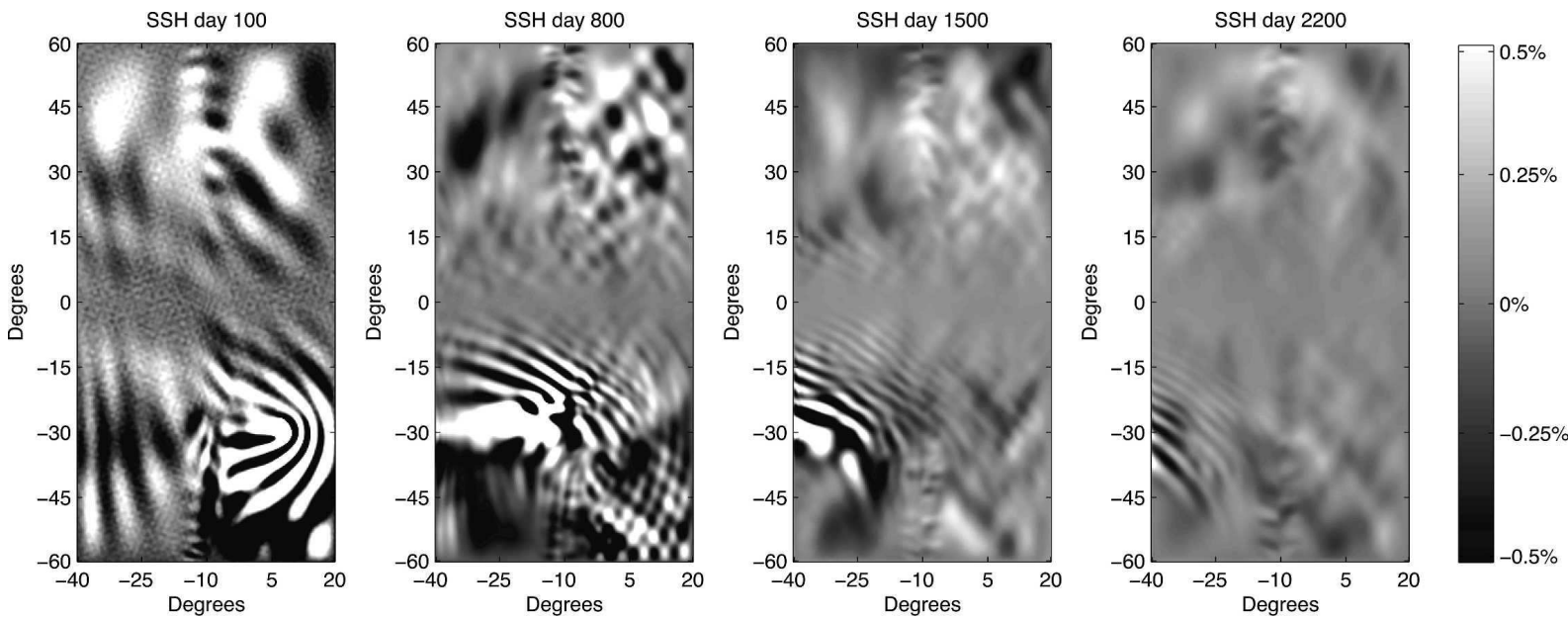

FIG. 7. Four snapshots of the sea surface height in the model run with a ridge. The scale runs from $-0.5 \%$ to $0.5 \%$ of the initial maximum ring height $(0.5 \mathrm{~m})$.

tions are discussed in the appendix. In the runs, the model is initiated without any Agulhas ring in order to facilitate the spinup of the MOC. After 2500 and 4000 days in the flux-driven and pressure-driven implementation, respectively, the overturning strength $\Psi$ is in a statistical steady state.

When the two parameterizations have fully spun up, an Agulhas ring is released. Figure 9 shows the response of the overturning circulation to this release event. In the figure, the response of the overturning on a ring has been compared with the response without a ring, yielding the following quantity:

$$
\tilde{\Psi}_{\text {diff }}=\tilde{\Psi}_{\text {Ring }}-\tilde{\Psi}_{\text {NoRing }} .
$$

To eliminate small-scale fluctuations, a 50-day moving average of $\tilde{\Psi}$ has been used. The confidence level, given as twice the standard deviation, is shown is gray. The magnitude of the response is different in the two parameterizations, where the flux-driven one yields 10-times-higher overturning strength fluctuations. This is partly due to the choice of tuning parameters, which gives the flux-driven parameterization a much higher sensitivity than the pressure-driven parameterization.

Both parameterizations agree that a ring enhances the overturning strength between 1300 and 1500 days after release. The first instance at which the overturning difference is significantly ( $2 \sigma$ or $99 \%$ significant) nonzero for an extended time is after 1300 days. Before
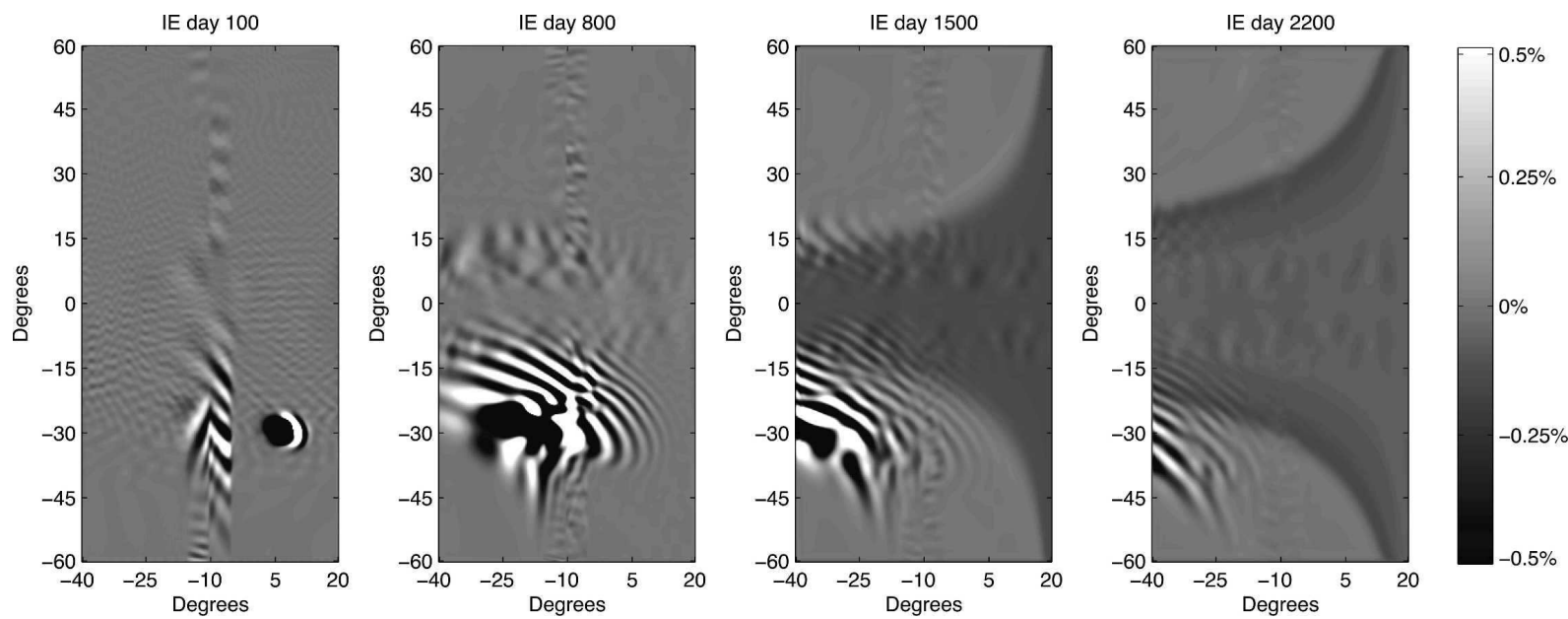

FIG. 8. Four snapshots of the interface elevation in the model run with a ridge. The scale runs from $-0.5 \%$ to $0.5 \%$ of the initial maximum interface depression $(200 \mathrm{~m})$. 

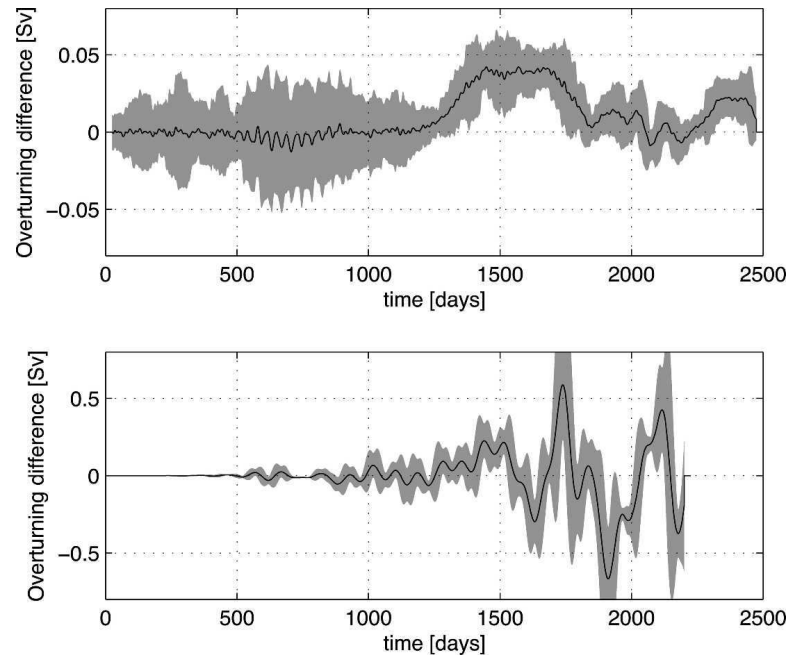

FIG. 9. The overturning strength difference $\left(\tilde{\Psi}_{\text {Ring }}-\tilde{\Psi}_{\text {NoRing }}\right)$ for the (top) pressure-driven and (bottom) flux-driven parameterization, both in the model configuration without a Mid-Atlantic Ridge. The gray area denotes the $2 \sigma$ confidence interval. Note the difference in vertical scales.

this, essentially nothing happens to the overturning parameterizations. Beyond 1500 days, the flux-driven parameterization gets unstable, which results in large fluctuations in the overturning strength. Apparently, the feedbacks are much stronger than in the pressuredriven parameterization. In this last implementation, the overturning strength difference returns to zero after 1800 days.

The presence of a Mid-Atlantic Ridge in the basin does not drastically change the overturning difference (not shown). The first significant nonzero difference occurs after 1300 days in both parameterizations. After that, the overturning difference stays positive until day 2000 in the pressure-driven parameterization, somewhat longer than without a ridge.

\section{Summary and discussion}

A set of numerical experiments has been conducted to investigate the energy transit time and route of Agulhas ring-like perturbations traveling to the North Atlantic Ocean. Particular attention has been given to the role of the Mid-Atlantic Ridge on the shortcutting of the route and time scale on which baroclinic energy is transported northward.

The model runs show that the time it takes for barotropic energy to be radiated to the northernmost part of the model basin is on the order of 10 days, although the bulk arrives after 500 days. In a flat-bottom basin, the amount of baroclinic energy increases after 1300 days, yielding the baroclinic time scale. Because of the large difference in Kelvin and Rossby phase speeds, this scale is largely determined by the transit time of the ring traveling from its initial position to the western boundary of the basin. It will therefore be sensitive to the latitude at which the ring travels (through the Rossby phase speed) and the zonal distance between the coasts.

When a 1000-m-high meridional ridge is placed on the ocean floor, the level of baroclinic energy between $45^{\circ}$ and $55^{\circ} \mathrm{N}$ is high from initiation onward. The ridge is capable of converting barotropic energy to baroclinic energy and this mechanism shortcuts the slow westward path of the ring.

One can debate this conclusion by remarking that the longitude at which the baroclinic energy enters the northernmost part of the model basin is different in the two model configurations. In the flat-bottom run, the energy enters near the eastern coast. In the configuration with a ridge, on the other hand, it is released on the ridge. The exact location of NADW formation seems to be more in the Greenland-Iceland-Norwegian (GIN) and Labrador Seas. The time it takes for the baroclinic energy to zonally cross half the basin at high latitudes is even larger than the 1300 days presented here. The conclusion that the ridge significantly reduces the response time scale is therefore still valid.

The MOC, implemented with two different parameterizations, responds with a significant increase in strength 1300 days after the ring has been released. In the flux-driven parameterization, the overturning gets unstable after that but in the pressure-driven the overturning returns to normal strength 1800 days after the ring has been released. This means that the overturning strength is affected for almost $1.5 \mathrm{yr}$ on this Agulhas ring. As rings shed every two months, one might expect (nonlinear) interactions between multiple rings further enhancing the overturning response. This can be the topic of further research.

The presence of a Mid-Atlantic Ridge does not reduce the time it takes for the overturning to respond. This is in contrast to the baroclinic energy level, which clearly shows a reduction in transfer time. Apparently, the amount of energy transferred to the northern part of the basin by the ridge is insufficient to alter the overturning strength in this last parameterization. The typical time scale encountered in this research (on the order of $3 \mathrm{yr}$ ) is similar to that found by Johnson and Marshall (2002b), but shorter than the time scales found by Primeau (2002) and Cessi and Otheguy (2003). In both latter cases, however, this is due to the smaller zonal extend of the basin, and in Primeau (2002) the somewhat smaller baroclinic Rossby deformation radius also increases the zonal transit time. In 
all experiments, this zonal transit time sets the time scale and the physical mechanisms are therefore not different.

This study is idealized in many ways. For one, the wind-driven gyres have not been implemented. It is expected that this omission will have little effect on the transit time in the South Atlantic, since the Agulhas rings swiftly enter the central latitude of the subtropical gyre and indeed take about 3 yr to cross the Atlantic basin in reality. Part of the ring water enters the Benguela Current, but the mean flow velocities of the current and its westward extension are similar to that of the ring velocity.

The scale that is used in Figs. 2 and 7 is $0.02 \mathrm{~m}$, but how significant is such a sea surface deviation? One can only say that the time scales presented in this paper are significant in the sense that they emerge from both the energy level analysis and the overturning parameterization. A $0.05-S v$ change in overturning strength per ring is not very large, but as said before some eight rings may shed in the $1.5 \mathrm{yr}$ that the overturning is affected. Given that the overturning is solely increased by a ring, multiple rings may reinforce each other to significant overturning changes.

In the turbulent real ocean, the ring signal will be diluted. In the North Atlantic Ocean, part of the ring energy will end up in the Gulf Stream and be carried farther northward. However, the advective time scales will be larger than the propagation speed of the adjustment Kelvin waves (see, e.g., Weijer et al. 2002). It is again the dilution of the signal that will reduce its significance. On the other hand, as shown by Weijer et al. (2002), the salt anomaly related to the Agulhas ring tends to strengthen on its northward journey as a result of excess evaporation. This increases the influence of the rings. Since our model is adiabatic these phenomena could not be studied and we concentrate on the baroclinic wave energy.

Acknowledgments. This work was sponsored by the SRON User Support Programme under Grant EO-079 and the Stichting Nationale Computerfaciliteiten [National Computing Facilities Foundation (NCF)] for the use of supercomputer facilities, with financial support from the Nederlandse Organisatie voor Wetenschappelijk Onderzoek [Netherlands Organization for Scientific Research (NWO)].

\section{APPENDIX}

\section{Implementation of the Overturning Circulation}

One of the few implementations of overturning circulations in a two-layer model in the literature is due to Andersson and Veronis (2004). In their model, the mass flux is set to a prescribed value, and then used to exchange mass between layers with vertical velocity $w_{0}(x, y)$. With an appropriate choice of $w_{0}(x, y)$, this is an overturning in the sense that what is removed from the upper layer can be inserted in the lower layer in the downwelling region and vice versa in the upwelling region.

This description cannot be used in our experiment because $w_{0}$ must be an observable instead of a parameter. What we need therefore is a relation between some observable in the model $f(h, u, v)$ and the overturning strength $\Psi$. In this case

$$
f(h, u, v) \propto \Psi=\int w_{0} d A,
$$

in which $d A$ is the region where the overturning is applied.

The $\Psi$ as calculated in relation (A1) can be very sensitive. Therefore, this relation is implemented with $\Psi$ as the mean of the different $\Psi$ s of the last 30 days. In this way, noise due to feedback mechanisms is drastically reduced.

\section{a. A pressure-driven parameterization}

To get an expression for $\Psi$ in terms of $h, u$, and $v$, the linear relation found by Weijer et al. (2002) can be used. It relates the zonally averaged meridional largescale pressure gradient to the NADW production. The relation can be implemented by computing the difference in zonally averaged pressure at the sea surface between two prescribed latitudes. Using hydrostatic equilibrium, this yields a relation that only involves the zonally averaged sea surface height $\tilde{\eta}$ :

$$
\Psi=\Psi_{0}+c \Delta P_{\mathrm{NS}}=\Psi_{0}+c \int_{-H_{1}}^{0}\left(\int_{-H_{0}}^{\tilde{\eta}_{N}} \rho_{1} g d z-\int_{-H_{0}}^{\tilde{\eta}_{S}} \rho_{1} g d z\right) d z=\Psi_{0}+c H_{1} \rho_{1} g\left[\tilde{\eta}\left(\theta_{N}\right)-\tilde{\eta}\left(\theta_{S}\right)\right]
$$

where $H_{1}=500 \mathrm{~m}$ is the undisturbed upper-layer depth and $H_{0}$ is the level of no motion. In Weijer et al. (1999),
$H_{0}=1500 \mathrm{~m}$, but in our case it drops out and does not have to be specified. The bias $\Psi_{0}=1.0 \mathrm{~Sv}$ is required 
to initiate the overturning circulation from an ocean at rest and $c=-7.5 \mathrm{~m}^{3} \mathrm{~s} \mathrm{~kg}^{-1}$ is the slope that has been determined by Weijer et al. (1999).

The latitudes at which $\tilde{\eta}$ is calculated are still open. Weijer et al. (2002) used $\theta_{N}=53^{\circ} \mathrm{N}$ and $\theta_{S}=30^{\circ} \mathrm{S}$. We have used several values for $\theta_{N}$ and $\theta_{S}$ to test the sensitivity of the results. The sections $\theta_{N}$ and $\theta_{S}$ were always on different hemispheres. The large-scale features of the responses are not very sensitive to the exact choice of latitudes.

It is obvious that this implementation for the overturning strength is not optimal. First, there is no indication that the linear relation, which was deduced from a thermohaline multilevel model, can be used in this highly simplified adiabatic model. Second, the use of (A2) only effectively takes the sea surface height into account. By doing this, the distinction between barotropic and baroclinic signals is neglected. This is an issue, as it was argued before that only the baroclinic signals can directly influence the MOC.

\section{b. A flux-driven parameterization}

A different approach is to return to the conceptual idea of the overturning circulation. When the upper layer of the model represents the northward-flowing limb of the circulation and the lower one, the return flow, mass conservation can be used to formulate the overturning: at some latitude, the mass difference between the inflow through the upper layer and the outflow through the lower layer must be transported from the upper to the lower layer. This transport then is the NADW formation and its magnitude is $\Psi$.

The formulation of the flux-driven overturning circulation can be written as

$$
\Psi=\Psi_{0}+\frac{1}{2}\left(\int_{\theta_{N}} v_{1} h_{1} d x-\int_{\theta_{N}} v_{2} h_{2} d x\right),
$$

where $\theta_{N}=40^{\circ} \mathrm{N}$ is the latitude at which the fluxes are calculated. Note that this equation uses the volumetric fluxes, instead of the mass fluxes. Using the Boussinesq approximation, however, these are equal. Further note that only baroclinic signals have an effect on $\Psi$ in this parameterization.

This implementation also has its drawbacks. In this formulation, it is assumed that all excess water north of a certain latitude will participate in the North Atlantic Deep Water formation. In the real ocean, however, water in the upper layer could be stored north of $40^{\circ} \mathrm{N}$ for some time to be released later as a southward flux. However, indirect support for this parameterization comes from observations, since this is the way in which the strength of the MOC is measured (e.g., Bryden et al. 2005).

\section{REFERENCES}

Anderson, D., and P. Rowlands, 1976: The role of inertia-gravity and planetary waves in the response of a tropical ocean to the incidence of an equatorial Kelvin wave on a meridional boundary. J. Mar. Res., 34, 295-312.

Andersson, H., and G. Veronis, 2004: Thermohaline circulation in a two-layer model with sloping boundaries and a mid-ocean ridge. Deep-Sea Res. I, 51, 93-106.

Barnier, B., 1988: A numerical study of the Mid-Atlantic Ridge on nonlinear first-mode baroclinic Rossby waves generated by seasonal winds. J. Phys. Oceanogr., 18, 417-433.

Beismann, J., R. Käse, and J. Lutjeharms, 1999: On the influence of submarine ridges on translation and stability of Agulhas rings. J. Geophys. Res., 104, 7897-7906.

Boebel, O., J. Lutjeharms, C. Schmid, W. Zenk, T. Rossby, and C. Barron, 2003: The Cape Cauldron, a regime of turbulent inter-ocean exchange. Deep-Sea Res. II, 50, 57-86.

Broecker, W., 1997: Thermohaline circulation, the Achilles heel of our climate system: Will man-made $\mathrm{CO}_{2}$ upset the current balance. Science, 278, 1582-1588.

Bryden, H., H. Longworth, and S. Cunningham, 2005: Slowing of the Atlantic meridional overturning circulation at $25^{\circ} \mathrm{N}$. $\mathrm{Na}$ ture, 438, 655-657.

Cessi, P., and P. Otheguy, 2003: Oceanic teleconnections: Remote response to decadal wind forcing. J. Phys. Oceanogr., 33, 1604-1617.

Clark, P., N. Pisias, T. Stocker, and A. Weaver, 2002: The role of the thermohaline circulation in abrupt climate change. $\mathrm{Na}$ ture, 415, 863-869.

De Ruijter, W., A. Biastoch, S. Drijfhout, J. Lutjeharms, R. Matano, T. Pichevin, P. J. Van Leeuwen, and W. Weijer, 1999: Indian-Atlantic interocean exchange: Dynamics, estimation and impact. J. Geophys. Res., 104, 20 885-20 910.

- , H. Ridderinkhof, and M. Schouten, 2005: Variability of the southwest Indian Ocean. Philos. Trans. Roy. Soc. London A, 363, 63-76.

De Steur, L., P. J. Van Leeuwen, and S. Drijfhout, 2004: Tracer leakage from modelled Agulhas rings. J. Phys. Oceanogr., 34, 1387-1399.

Drijfhout, S., C. Katsman, L. De Steur, P. Van der Vaart, P. J. Van Leeuwen, and C. Veth, 2003: Modeling the initial, fast sea-surface height decay of Agulhas Ring "Astrid." Deep-Sea Res. II, 50, 299-319.

Ganachaud, A., and C. Wunsch, 2000: Improved estimates of global ocean circulation, heat transport and mixing from hydrographic data. Nature, 408, 453-456.

Gordon, A., 1986: Interocean exchange of thermocline water. $J$. Geophys. Res., 91, 5037-5046.

Johnson, H., and D. Marshall, 2002a: Localization of abrupt change in the North Atlantic thermohaline circulation. Geophys. Res. Lett., 29, 1083, doi:10.1029/2001GL014140.

$\longrightarrow$, and — 2002b: A theory for the surface Atlantic response to thermohaline variability. J. Phys. Oceanogr., 32, 11211132.

Kamenkovitch, V., Y. Leonov, D. Nechaev, D. Byrne, and A. Gordon, 1996: On the influence of bottom topography on the Agulhas eddy. J. Phys. Oceanogr., 26, 892-912.

Knorr, G., and G. Lohmann, 2003: Southern Ocean origin for the 
resumption of Atlantic thermohaline circulation during deglaciation. Nature, 424, 532-536.

Kowalik, Z., and T. Murty, 1993: Numerical Modelling of Ocean Dynamics. Advanced Series on Ocean Engineering, Vol. 5, World Scientific, $496 \mathrm{pp}$.

Liu, Z., L. Wa, and E. Baler, 1999: Rossby wave-coastal Kelvin wave interaction in the extratropics. Part I: Low-frequency adjustment in a closed basin. J. Phys. Oceanogr., 29, 23822404.

Longuet-Higgins, M., 1965: The response of a stratified ocean to stationary or moving wind-systems. Deep-Sea Res., 12, 923 973.

Lutjeharms, J., 1996: The exchange of water between the South Indian and South Atlantic Oceans. The South Atlantic: Present and Past Circulation, G. Wefer et al., Eds., SpringerVerlag, 125-162.

Mesinger, F., and A. Arakawa, 1976: Numerical methods used in atmospheric models. GARP Publications, World Meteorological Organization, $71 \mathrm{pp}$.

Nof, D., 1983: On the migration of isolated eddies with application to Gulf Stream rings. J. Mar. Res., 41, 399-425.

Peeters, F., R. Acheson, G. Brummer, W. De Ruijter, R. Schneider, G. Ganssen, E. Ufkes, and D. Kroon, 2004: Vigorous exchange between the Indian and Atlantic Oceans at the end of the past five glacial periods. Nature, 430, 661-665.

Primeau, F., 2002: Long Rossby wave basin-crossing time and the resonance of low-frequency basin modes. J. Phys. Oceanogr., 32, 2652-2665.

Rahmstorf, S., 1996: On the freshwater forcing and transport of the Atlantic thermohaline circulation. Climate Dyn., 12, 799811.

- and A. Ganopolsky, 1999: Long-term global warming sce- narios computed with an efficient coupled climate model. Climatic Change, 43, 353-367.

Saenko, O., J. Gregory, A. Weaver, and M. Eby, 2002: Distinguishing the influence of heat, freshwater, and momentum fluxes on ocean circulation and climate. J. Climate, 15, 36863697.

Schmitz, W., Jr., 1995: On the interbasin-scale thermohaline circulation. Rev. Geophys., 33, 151-173.

Schouten, M., W. De Ruijter, P. J. Van Leeuwen, and J. Lutjeharms, 2000: Translation, decay and splitting of Agulhas rings in the southeastern Atlantic Ocean. J. Geophys. Res., 105, $21913-21925$.

Tailleux, R., 2004: A WKB analysis of the surface signature and vertical structure of long extratropical baroclinic Rossby waves over topography. Ocean Modell., 6, 191-219.

- and J. McWilliams, 2000: Acceleration, creation, and depletion of wind-driven, baroclinic Rossby waves over an ocean ridge. J. Phys. Oceanogr., 30, 2186-2213.

Tang, C., 1979: Development of radiation fields and baroclinic eddies in a $\beta$-plane. J. Fluid Mech., 93, 379-400.

Van Aken, H., A. Van Veldhoven, C. Veth, W. De Ruijter, P. J. Van Leeuwen, S. Drijfhout, C. Whittle, and M. Rouault, 2003: Observations of a young Agulhas ring, Astrid, during MARE in March 2000. Deep-Sea Res. II, 50, 167-195.

Wang, L., and C. Koblinsky, 1994: Influence of mid-ocean ridges on Rossby waves. J. Geophys. Res., 99, 25 143-25 153.

Weijer, W., W. De Ruijter, H. Dijkstra, and P. J. Van Leeuwen, 1999: Impact of interbasin exchange on the Atlantic overturning circulation. J. Phys. Oceanogr., 29, 2266-2284.

,-- A. Sterl, and S. Drijfhout, 2002: Response of the Atlantic overturning circulation to South Atlantic sources of buoyancy. Global Planet. Change, 34, 293-311. 